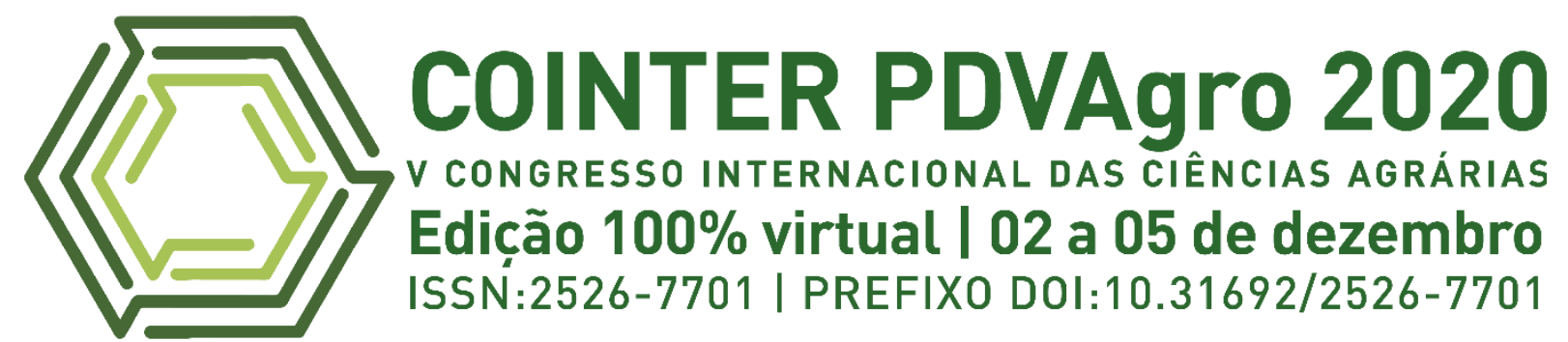

\title{
CONTROLE DO MOISACO SEVERO EM FEIJÃO-CAUPI
}

\author{
CONTROL DE MOSAICO SEVERO EN CAUPI
}

\section{CONTROL OF SEVERE MOSAIC IN CAUPI BEANS}

\author{
Apresentação: Comunicação Oral \\ Gisele Silva Oliveira ${ }^{1}$; Alciele da Silva Leite ${ }^{2}$; Jane Clésia Silva dos Santos ${ }^{3}$ Thiago Henrique Cavalcanti de \\ Mendonça ${ }^{4}$; Denise de Santana Silva ${ }^{5}$
}

DOI: $\underline{\text { https://doi.org/10.31692/2526-7701.VCOINTERPDVAgro.0677 }}$

\begin{abstract}
RESUMO
A produtividade média do feijão-caupi é baixa, devido aos poucos aparatos tecnológicos empregados, sendo cultivado, predominantemente, por agricultores familiares, por ser considerada uma cultura de subsistência. Tendo em vista que a importância desta leguminosa tanto no mundo, quanto na agricultura, especificamente para o meio ambiente e a nutrição humana, tem feito com que os programas de melhoramento busquem genótipos resistentes às diversas doenças. Diante dos problemas fitossanitários relacionados ao feijão-caupi no Brasil, o cultivo desta leguminosa pode ser afetado por diversos patógenos, como fungos, bactérias, vírus e nematoides, que podem causar a morte de plantas e, consequentemente, ocasionar prejuízos econômicos. Entre as várias doenças que ocorrem no desenvolvimento do caupi, vale destacar o mosaico severo, que prejudica em larga escala o crescimento e a produção das plantas. Devido à severidade desta doença e à falta de substâncias químicas para controlar o vírus nas plantas de feijão-caupi, o uso de medidas preventivas têm sido o mais viável, através do uso de sementes certificadas, eliminação do controle de vetores de origem viral variedades resistentes. Diante disso, o objetivo deste trabalho é identificar e descrever métodos de controle eficazes para a prevenção do vírus mosaico severo no feijão-caupi. O trabalho consiste em uma revisão de literatura, construída a partir de buscas nos bancos de pesquisas, Portal de periódicos CAPES e Google acadêmico, por meio de artigos científicos, livros e monografias, no período de 2015 a 2020. A pesquisa é de cunho qualitativo. Os trabalhos encontrados foram avaliados e aqueles que abordavam assuntos relacionados a pesquisa foram utilizados. Serão discutidos a seguir resultados encontrados nas pesquisas realizadas, referente ao tema abordado. A virose causada pelo vírus do mosaico severo no feijão-caupi, é classificada como: suscetível, resistente ou imune, tendo em vista que essa classificação está relacionada às reações sintomáticas presentes no vírus de acordo com seu desenvolvimento na planta. Na pesquisa foi possível concluir que a utilização de genótipos resistentes, tem sido a forma mais eficaz no controle do mosaico severo, visto que é uma doença de difícil controle e que também não se tem no

\footnotetext{
${ }^{1}$ Graduanda do curso de Bacharelado em Agronomia, Instituto Federal de Educação, Ciência e Tecnologia de Pernambuco, Liveirag@gmail.com

${ }^{2}$ Graduanda do curso de Bacharelado em Agronomia, Instituto Federal de Educação, Ciência e Tecnologia de Pernambuco, alcieleleite@gmail.com

${ }^{3}$ Graduanda do curso de Bacharelado em Agronomia, Instituto Federal de Educação, Ciência e Tecnologia de Pernambuco,janeclsia28@gmail.com

${ }^{4}$ Graduando do curso de Bacharelado em Agronomia, Instituto Federal de Educação, Ciência e Tecnologia de Pernambuco, Thiago.cavalcanti2511@gmail.com

${ }^{5}$ Mestre, Instituto Federal de Educação, Ciência e Tecnologia de Pernambuco, Denise.santana@ vitoria.ifpe.edu.br
} 


\title{
CONTROLE DO MOSAICO SEVERO EM FEIJÃO-CAUPI
}

mercado inseticidas eficientes.

Palavras-Chave: Cowpea mosaic vírus, Melhoramento genético, Vigna unguiculata.

\section{RESUMEN}

La productividad media del caupí es baja, debido a los pocos dispositivos tecnológicos utilizados, siendo cultivado, predominantemente, por agricultores familiares, por ser considerado una cultura de subsistencia. Teniendo en cuenta que la importancia de esta leguminosa tanto en el mundo como en la agricultura, específicamente para el medio ambiente y la nutrición humana, ha llevado a los programas de mejoramiento a buscar genotipos resistentes en diversas enfermedades. En vista de los problemas fitosanitarios relacionados con el caupí en Brasil, el cultivo de esta leguminosa puede verse afectada por varios patógenos, como hongos, bacterias, virus y nematodos, que pueden causar la muerte de las plantas $\mathrm{y}$, en consecuencia, causar pérdidas económicas. Entre las diversas enfermedades que ocurren en el desarrollo del caupí, cabe mencionar el mosaico severo, que perjudica en gran medida el crecimiento y producción de las plantas. Debido a la gravedad de esta enfermedad y la falta de sustancias químicas para controlar el virus en plantas de caupí, el uso de medidas preventivas ha sido lo más viable, mediante el uso de semillas certificadas, eliminación del control de vectores de variedades resistentes a virus. Por lo tanto, el objetivo de este trabajo es identificar y describir métodos de control efectivos para la prevención del virus del mosaico severo en el caupí. El trabajo consiste en una revisión de la literatura, construida a partir de búsquedas en los bancos de investigación, Portal de revistas CAPES y académico de Google, a través de artículos científicos, libros y monografías, en el período de 2015 a 2020 . La investigación es de carácter cualitativo. Se evaluaron los trabajos encontrados y se utilizaron aquellos que abordaban temas relacionados con la investigación. A continuación se comentarán los resultados encontrados en la investigación realizada sobre el tema abordado. La virosis causada por el virus del mosaico severo en el caupí se clasifica en: susceptible, resistente o inmune, considerando que esta clasificación está relacionada con las reacciones sintomáticas presentes en el virus según su desarrollo en la planta. En la investigación se pudo concluir que el uso de genotipos resistentes, ha sido la forma más efectiva de controlar el mosaico severo, ya que es una enfermedad de difícil control y que tampoco existen insecticidas eficientes en el mercado.

Palabras Clave: Virus del mosaico del caupí, Mejora genética, Vigna unguiculata.

\begin{abstract}
The average productivity of cowpea is low, due to the few technological devices used, being cultivated, predominantly, by family farmers, as it is considered a subsistence culture. Bearing in mind that the importance of this legume both in the world and in agriculture, specifically for the environment and human nutrition, has led breeding programs to search for genotypes resistant at various diseases. In view of the phytosanitary problems related to cowpea in Brazil, the cultivation of this legume can be affected by several pathogens, such as fungi, bacteria, viruses and nematodes, which can cause the death of plants and, consequently, cause economic losses. Among the various diseases that occur in the development of cowpea, it is worth mentioning the severe mosaic, which largely impairs the growth and production of plants. Due to the severity of this disease and the lack of chemical substances to control the virus in cowpea plants, the use of preventive measures has been the most viable, through the use of certified seeds, elimination of vector control of viral resistant varieties. Therefore, the objective of this work is to identify and describe effective control methods for the prevention of severe mosaic virus in cowpea. The work consists of a literature review, built from searches in the research banks, Portal of CAPES journals and Google academic, through scientific articles, books and monographs, in the period from 2015 to 2020 . The research is of a qualitative nature. The works found were evaluated and those that addressed subjects related to research were used. The results found in the research carried out on the topic addressed will be discussed below. Virosis caused by the severe mosaic virus in cowpea is classified as: susceptible, resistant or immune, considering that this classification is related to the symptomatic reactions present in the virus according to its development in the plant. In the research it was possible to conclude that the use of resistant genotypes, has been the most effective way to control the severe mosaic, since it is a disease of difficult control and that there are also no efficient insecticides on the market.
\end{abstract}

Keywords: Cowpea mosaic virus, Genetic improvement, Vigna unguiculata. 


\section{INTRODUÇÃO}

A área de produção do feijão-caupi em todo território mundial chega a aproximadamente 12,3 milhões de hectares, ao qual a África teve contribuição de 12 milhões de ha, seguido da América, Ásia e Europa com 72, 155 ha, segundo a Food and Agricultural Organization (FAO, 2018).

Nas regiões Norte e Nordeste concentra-se grande parte da produção do feijão-caupi, entretanto vem ocorrendo uma expansão direcionada a região Centro-oeste, especificamente para o estado do Mato Grosso, tendo em vista que o cultivo passou a ser produzido em uma escala maior (BASTOS, 2016).

A produtividade média do feijão-caupi é baixa, devido aos poucos aparatos tecnológicos empregados, sendo cultivado, predominantemente, por agricultores familiares, por ser considerada uma cultura de subsistência, sem a adoção de práticas adequadas, como irrigação, controle de pragas e doenças (BEZERRA, 2016).

Entretanto, o feijão-caupi vem ganhando maior expressão econômica em algumas regiões do Brasil, devido a seu expressivo consumo, tendo em vista também que o plantio está deixando apenas de ser de subsistência para atingir áreas maiores, e isso está dentro dos padrões agronômicos favoráveis ao desenvolvimento da cultura, melhorando ainda mais sua produtividade (AGEITEC, 2018).

De acordo com Bezerra (2016), Vigna unguiculata L. Walp. possui algumas denominações que variam em cada região, no Nordeste do Brasil é conhecido como feijão macassar, feijão-de-corda, feijão-de-praia, feijão da colônia, porém o mais utilizado é o termo feijão-caupi.

É uma leguminosa herbácea, anual, produz frutos do tipo legume, suas raízes podem atingir cerca de dois metros de profundidade, tendo em vista que essa característica auxilia a planta a resistir ao período de seca e, dependendo da variedade, pode apresentar variação na altura da planta. E possui também propriedades proteicas, minerais, além de ser rico em fibras (COÊLHO, 2018).

A importância desta leguminosa tanto no mundo, quanto na agricultura, especificamente para o meio ambiente e a nutrição humana, tem feito com que os programas de melhoramento busquem genótipos resistentes a diversas doenças (ARAÚJO, 2015).

Diante dos problemas fitossanitários relacionados ao feijão-caupi no Brasil e em alguns países, o cultivo desta cultura é afetado por diversos patógenos, como fungos, bactérias, vírus e nematóides, que podem causar a morte de plantas e, consequentemente, ocasionar prejuízos econômicos. Entre as várias doenças que ocorrem no desenvolvimento do feijão-caupi, vale 


\section{CONTROLE DO MOSAICO SEVERO EM FEIJÃO-CAUPI}

destacar o mosaico severo, que prejudica em larga escala o crescimento e a produção das plantas (LIMA, 2017).

No Brasil, forma descritos nove espécies de vírus que acometem o feijão-caupi, dentre eles destacam-se por sua predominância no campo: Cumcuber mosaic vírus (CMV), Cowpea aphid-borne mosaic vírus (CABMV), Cowpea mosaic vírus (CPSMV) e Cowpea mild mottle virus (LAMAS et al., 2017).

Os sintomas exibidos no feijão-caupi são graves em variedades suscetíveis, quando os sintomas aparecem em plantas jovens, os mesmos são mais pronunciados na parte aérea da planta, incluindo necrose na extremidade superior do caule, morte do botão terminal e queda prematura da folha, já nas folhas são: clorose, manchas necróticas, mosaico severo, deformação foliar, redução da folha, bolhas, necrose sistêmica e morte. Dependendo das espécies envolvidas e do tempo de inoculação, os danos à produção são altos (LIMA, 2015).

Devido à severidade da doença e à falta de substâncias químicas para controlar os vírus nas plantas de feijão-caupi, o uso de medidas preventivas têm sido o mais viável, visto que o objetivo é reduzir a fonte de inoculação dentro e fora da plantação, como o uso de sementes certificadas, eliminação do controle de vetores de origem viral e o uso de variedades resistentes (LIMA, 2015). Na prática efetiva de manejo de doenças do feijoeiro, destaca-se o uso de variedades resistentes a diferentes isolados do CPSMV (PIO RIBEIRO et al., 2016).

Diante disso, o objetivo deste trabalho é identificar e descrever métodos de controle eficazes para a prevenção do vírus mosaico severo no feijão-caupi.

\section{FUNDAMENTAÇÃO TEÓRICA}

\section{Aspectos gerais do feijão-caupi}

O feijão-caupi é cultivado em todas as áreas do país, porém tem predominância nas regiões Norte e Nordeste. No Nordeste, a produção de grãos em 2014 foi de 674.659 toneladas e a produtividade atingiu $438 \mathrm{~kg} / \mathrm{ha}$. Tendo em vista que os maiores produtores de área plantada são: Bahia (357.311 toneladas), Ceará (109.148 toneladas), Piauí (55.278 toneladas) e Pernambuco (52.787 toneladas) (IBGE, 2015).

Por esta cultura representar uma importante fonte de proteína para alimentação humana, tendo em vista também ser um dos principais componentes alimentares para a população rural (ARAÚJO, 2015; ANDRADE et al., 2020).

A principal fonte de emprego e renda nas regiões Norte e Nordeste do Brasil é o cultivo de feijão-caupi, especialmente no sertão nordestino, sendo parte da produção direcionada para alimentação dessa população e o excedente comercializado (LINHARES et al., 2016). 
A produção no Brasil vem da agricultura familiar e do setor empresarial rural, que atende à demanda do mercado interno com vagens verdes, grãos secos e sementes (OLIVEIRA et al., 2017). Tendo em vista que a maior parte da produção se concentra nas áreas de sequeiro dos pequenos e médios produtores, por essa leguminosa ser considerada de subsistência familiar (LINHARES et al., 2016).

O feijão-caupi é uma planta dicotiledônea, pertence à ordem Fabales, família Fabaceae, gênero Vigna e espécie Vigna unguiculata (L.) Walp.) (OLIVEIRA, 2017; AKBAR, 2020). Seu cultivo ocupa 12, 5 milhões de hectares, sendo que oito milhões de ha estão localizados na região central e oeste da África, correspondendo a 64\% da área mundial cultivada, tendo também importantes áreas de produção na América do Sul, América Central e Ásia, no entanto a produção no sudoeste da Europa, sudoeste dos Estados Unidos e da Oceania, ainda estão em expansão, representando uma área menor de cultivo quando comparadas com os outros lugares (DAMACENO E SILVA et al., 2016; SOUZA, 2016).

O feijão-caupi, é amplamente conhecido como feijão de corda no Nordeste do Brasil, sendo um dos principais alimentos da região, fornecendo carboidratos, proteínas e ferro. É cultivado principalmente por agricultores em pequenas propriedades e é uma fonte de emprego e renda. Atualmente, médios e grandes produtores do Cerrado estão cultivando na forma de safrinha e adotam técnicas de produção comercial, como a soja [Glycine max (L.) Merril], que pode aumentar a produção e a oferta desse grão (VALE; BERTINI; BORÉM, 2017).

No mercado existe três segmentos para a cultura do feijão-caupi: grãos secos, feijão verde, vagem, grãos verdes e sementes. Levando em consideração que atualmente a produção está direcionada, principalmente, para atender o consumo de grãos secos, no entanto, está crescendo também a procura por vagens ou grãos verdes debulhados, aumentando cada vez mais a importância desses produtos para uma cadeia crescente de mercado (ALVES, 2020).

Com relação ao valor nutricional, o grão de feijão-caupi apresenta um conteúdo proteico variando entre 203 - 394 g, além de um baixo conteúdo de gorduras, quando comparado a outros legumes, como grão-de-bico, lentilha, ervilha e o e feijão-mungo, além de ser fonte de minerais, em especial Ferro, Zinco e Cálcio (GONÇALVES et al. 2016).

\section{Vírus mosaico severo no feijão-caupi}

O mosaico severo do feijão-caupi (CPSMV) é ocasionado pelo Cowpea severe mosaic vírus, família Secovidae, existindo apenas uma subfamília atualmente (Comovirinae) que envolve os gêneros Comovirus,Fabavirus e Nepovirus, ao qual mantém uma estreita relação filogeneticamente (THOMPSON et al., 2017). 


\section{CONTROLE DO MOSAICO SEVERO EM FEIJÃO-CAUPI}

De acordo com Andrade (2016), existem relatos de haver a presença desse vírus, além do Brasil, na Costa Rica, El Salvador, Estados Unidos, seguido do Peru, Porto Rico, Suriname, Trindad e Venezuela (PIO-RIBEIRO et al., 2016).

A transmissão do Cowpea severe mosaic se desenvolve de forma circulativa não propagativa, onde o vírus atinge a hemolinfa do inseto, em que persiste no corpo do vetor durante vários dias. Tendo em vista que a transmissão só ocorre de fato, quando o inseto vai se alimentar das plantas sadias de feijão-caupi e insere a saliva com partículas virais (FERERES et., 2015).

O feijão-caupi pode ser infectado por mais de 20 espécies de vírus de diferentes famílias e/ou gêneros, dentre os principais, destacam-se as espécies das seguintes famílias e gêneros: família Secoviridae, gênero Comovirus, Cowpea severe mosaic virus (CPSMV); família Potyviridae, gênero Potyvirus, Cowpea aphid-borne mosaic virus (CABMV), família Bromoviridae, gênero Cucumovirus, Cucumber mosaic virus (CMV) e família Geminiviridae, gênero Begomovirus, Cowpea golden mosaic virus (CGMV) (LIMA, 2015).

Os principais vetores de vírus são em sua maioria, artrópodes, especificamente insetos da ordem Hemiptera, que constitui o grupo mais recorrente (CARVALHO; COSTA, 2015). Dentre os insetos pragas transmissoras do vírus no feijão-caupi, destaca-se a vaquinha (Diabrotica speciosa), o pulgão preto (Aphis craccivora) e a mosca branca (Bemisa tabaci). (BLEICHER; SILVA, 2017).

A vaquinha apresenta coloração preto-amarela ou verde-amarela, e causa pequenos orifícios arredondados nas folhas do feijão-caupi, tendo em vista que essas lesões podem transmitir vírus. Já o pulgão preto mede cerca de $0,15 \mathrm{~cm}$ de comprimento, possui uma coloração que varia de amarelo-claro a verde-escuro, ao qual sobrevive nas folhas, flores, ramos, brotos novos e até mesmo na vagem, e por ser um inseto sugador transmite o vírus. $\mathrm{E}$ a mosca branca é um inseto pequeno, e como o próprio nome já diz, possui coloração branca e chega a medir 1,5 mm de comprimento, sendo também um transmissor do vírus (SILVA et al., 2019).

Os vírus merecem atenção especial devido às grandes reduções que causam na cultura, portanto é importante ter um diagnóstico correto e definitivo das fitomoléstias causada pelo os mesmos, devido ao fato de serem difíceis controlar (SILVA, 2017).

As doenças do feijão-caupi mostram grande relação com o ciclo fenológico, pois pode se desenvolver em qualquer estágio de desenvolvimento da planta, tendo em vista que o mosaico severo pode surgir na formação dos primeiros folíolos, até maturação, reduzindo assim a absorção fotossintética da planta (EMBRAPA, 2016). 
O mosaico severo causa infecções isoladas em plantas de feijão-caupi, afetando a produtividade e a qualidade nutricional das safras. Esses efeitos dependem da idade da planta infectada e de outros fatores (BEZERRA, 2016).

A reação do feijão-caupi ao vírus traz grandes perdas na produção, pois a redução foliar, mosaicos e necroses reduzem o painel fotossintético da planta, levando a uma baixa produtividade da cultura (KAUFFMANN et al., 2019).

A redução de produtividade ocasionada devido a incidência do mosaico devido ao ataque da vaquinha, chega a $80 \%$, porém isso depende da idade em que as plantas são afetadas, tendo como sintomas mais frequentes a bolhosidade, devido a formação do intenso encrespamento do limbo foliar, a alternância de cores nos folíolos, indo de verde-clara a verdeescura. E as sementes também são prejudicadas, pois como as mesmas vem de plantas atacadas, irão apresentar futuramente um percentual de germinação baixo, assim como, serão sementes deformadas, chochas e manchadas (EMBRAPA, 2016).

Em qualquer parâmetro de doenças em planta, mais especificamente as causadas por vírus, a utilização de genótipos resistentes, através da modificação do genoma é o método mais eficaz, pois visa a preservação do ambiente (CHANDRASEKARAN et al. 2016).

No entanto, é necessário regulamentações extensas, visto que o germoplasma são rastreados e avaliados, isso de acordo com a incidência da doença na planta estudada (BHATTARAI et al., 2017).

\section{Métodos de controle ao Mosaico Severo}

Existem vários métodos que podem ser usados para fazer um diagnóstico correto e definitivo de doenças causadas por vírus, os quais são divididos nas seguintes categorias: métodos biológicos baseados nas características biológicas dos vírus, uso de inseticidas contra o inseto vetor e a resistência genética (LIMA et al., 2015).

O Teste Biológico consiste na utilização do vírus em uma série de espécies de plantas que são inoculadas mecanicamente ou inoculadas naturalmente. Esses vírus apresentam as características de um vírus específico ou de um grupo de vírus Sintomas, em condições de estufa controladas. O diagnóstico é baseado na comparação dos sintomas observados com aqueles relatados na literatura (DIANESE; MEDEIROS, 2015; LIMA et al.; 2015).

Embora seja de grande ajuda na identificação e nas características biológicas dos vírus, devido às mutações naturais causadas por fatores relacionados a vírus, plantas e condições climáticas, estudos sobre a variedade de plantas hospedeiras raramente são usados como único diagnóstico conclusivo. Além do tempo longo para a observação dos resultados, o número de 


\section{CONTROLE DO MOSAICO SEVERO EM FEIJÃO-CAUPI}

espécie de vírus aumentou, impossibilitando sua identificação por esse método.

O uso de inseticidas para controlar insetos vetores pode não ser eficaz na prevenção do desenvolvimento de doenças, mas pode inibir a transmissão e, em qualquer caso, só é eficaz contra os vírus que têm uma relação cíclica com seus vetores. É importante saber o tipo de relação entre vírus e vetor (CARVALHO; COSTA, 2015).

Poucos ingredientes ativos são registrados para reduzir as pragas que ocorrem no feijãocaupi. Além disso, as opções de controle podem ser eficazes na redução de certas pragas, mas podem não resolver o problema de forma eficaz (BLEICHER; SILVA, 2017).

Lima (2015), também afirma que a utilização de inseticidas para o controle de outros vírus é inviável, em virtude da rapidez com que tais vírus são infectam as plantas, já que o vírus pode ser transmitido até na picada de prova. Embora os vetores morram algum tempo após terem se alimentado em plantas tratadas, a transmissão não é evitada, pois a maioria dos inseticidas age no sistema nervoso central do inseto, o que estimula bastante o inseto antes de morrer e faz com que a eficiência de transmissão seja maior e assim o inseto pica mais vezes e transmite mais o vírus.

De acordo com distribuição generalizada desta virose, a forma mais eficaz de controle ao mosaico é o emprego de cultivares comerciais resistentes, neste caso são indicados a BR 10Piauí, BR 14 Mulato e a BR 17- Gurguéia, levando em consideração também que é necessário observar a época de plantio e a eliminação de restos culturais contaminados (EMBRAPA, 2016).

O uso de variedades resistentes para controle de vírus em feijão tem importante significado econômico, incluindo o controle do mosaico severo (LIMA, 2015), este trabalho deve ser permanente porque a resistência incorporada nem sempre é durável. Durante sua evolução, o vírus formará uma estratégia de mutação ou recombinação coevoluindo com o hospedeiro, podendo destruir a resistência (FERREIRA, 2015).

\section{METODOLOGIA}

O trabalho consiste em uma revisão de literatura, construída a partir de buscas nos bancos de pesquisas, Portal de periódicos CAPES e Google acadêmico, por meio de artigos científicos, livros e monografias, no período de 2015 a 2020. A pesquisa é de cunho qualitativo. Os trabalhos encontrados foram avaliados e aqueles que abordavam assuntos relacionados a pesquisa foram utilizados. 


\section{RESULTADOS E DISCUSSÃO}

A virose causada pelo vírus do mosaico severo no feijão-caupi, é classificada como: suscetível, resistente ou imune (BEZERRA, 2016), tendo em vista que essa classificação está relacionada às reações sintomáticas presentes no vírus de acordo com seu desenvolvimento na planta.

Nos municípios de Belém e Tracuateua as coletas de feijão-caupi infectados por vírus, tem ocorrido a presença de Cowpea Aphid-Borne Mosaic Virus-CABMV, no entanto, em uma incidência menor, causando sintomas de severidade alta, sendo possível encontrar também a presença do Cowpea Severe Mosaic Vírus - CPSMV (LIMA, 2019), ao qual leva a um declínio na produtividade por ser um fator limitante de desenvolvimento da cultura.

Já em pesquisas realizadas por Lima (2019), foi possível observar nas plantas de feijãocaupi suscetíveis da geração F2 alguns sintomas, sendo eles, bolhosidade nas folhas, clareamento das nervuras, lesões locais cloróticas e necróticas.

Além desses, também se observou mosqueados que alternam de cor, indo de verde clara a verde escura, redução do limbo foliar e distorção foliar, estando de acordo com os sintomas de plantas infectadas com o mosaico severo, fazendo como que a produtividade seja baixa.

Silva (2017), afirma que a sintomatologia variou entre os isolados virais, o CPSMV apresentou sintomas como: lesões necróticas, mosaico Severo nas espécies vegetais inoculadas. Para as plantas de feijão-caupi os sintomas variaram de mosaico leve a mosaico severo com bolhosidade, tendo como variedade de resistência média a cultivar Marataoã que apresentou sintoma de mosaico leve, para este isolado. Onde a mesma pode ser disponibilizada para que os produtores tenham acesso a esse material.

Silva (2017), também afirma em suas pesquisas que a maior parte dos isolados de CPSMV, mantidos na cultivar Pitiúba, exibiu sintomas iniciais de mosaico, três a quatro dias após inoculação mecânica, evoluindo para mosaico severo, deformação foliar, redução do porte da planta. Tendo em vista que, está variedade não se mostra adequada para o plantio.

Em contrapartida, as inoculações nas cultivares avaliadas mostraram sintomas típicos de viroses, variando desde mosaico com necrose, redução e abscisão foliar até a morte da planta. Devido à ocorrência severa e permanente dessa virose em propriedades da região, a forma mais eficaz de controle é o uso de cultivares resistentes ao mosaico severo, assim como, o combate aos insetos vetores por monitoramento na época de plantio e eliminação plantas hospedeiras (KAUFFMANN et al., 2019).

A reação da planta ao vírus acarreta uma perda da produção da planta, pois a redução foliar, reduz o painel fotossintético da planta, levando a uma baixa produtividade da cultura, 


\section{CONTROLE DO MOSAICO SEVERO EM FEIJÃO-CAUPI}

por fim, a morte da planta leva a perda total de produção, deixando o produtor com prejuízos.

Em estudos realizados por José et al. (2019), foram identificadas 25 linhagens cujo valor de susceptibilidade foi $0 \%$, sendo consideradas resistentes ao CPSMV.

Estas linhagens foram multiplicadas e incluídas em experimentos preliminares, cujos principais parâmetros de interesse agronômico foram avaliados, com objetivo de desenvolver cultivares resistentes ao CPSMV para os próximos anos. Tendo em vista que esse material seja disponibilizado para programas de melhoramento, assim como para os pequenos e médios agricultores familiares.

De acordo com Lima (2019), foi possível constatar a presença de setecentos e cinquenta e três plantas com sintomas de infecção do mosaico severo e duzentos e sessenta e sete plantas sem sintomas, sendo estas consideradas resistentes ao vírus. O número considerando de plantas observadas sem sintomas foi próximo ao esperado. Diante disso, foi observado uma probabilidade de três plantas suscetíveis para uma planta resistente ao vírus. Onde esses dados se mostram satisfatórios.

\section{CONCLUSÕES}

A partir da revisão da literatura foi possível concluir que a utilização de genótipos resistentes tem sido a forma mais eficaz no controle do mosaico severo, visto que é uma doença de difícil controle e que também não se tem no mercado produtos fitossanitários eficientes para o controle da mesma.

\section{REFERÊNCIAS}

AGEITEC - Agência Embrapa de Informação Tecnológica. Disponível em: <http://www.agencia.cnptia.embrapa.br.>. Acesso em: 22 out. 2020.

AKBAR, S. Handbook of 200 Medicinal Plants: A Comprehensive Review of Their Traditional Medical Uses and Scientific Justifications. Springer Nature, 2020.

ALVES, A. S. S. C. Efeito de diferentes épocas do plantio de feijão-caupi (Vigna unguiculata (L.) Walp.) na dinâmica populacional de insetos-pragas e seus inimigos naturais.2020. Dissertação (Doutorado em produção vegetal) - Universidade Federal do Amazonas, Manaus, 2020.

ANDRADE, J. G.; SILVA, M. G.; OLIVEIRA FILHO, F. S.; FEITOSA, S. S. Diagnóstico das técnicas de produção e armazenamento de sementes crioulas em assentamentos rurais de Aparecida, Paraíba, Brasil. Research, Society and Development, v. 9, n. 5, 2020.

ARAÚJO, F. T. Genes de resistência a patógenos em feijão-caupi e em outras leguminosas: caracterização e diversidade. 2015. Dissertação (Mestrado em Genética) - Universidade 
Federal de Pernambuco, Recife, 2015.

BASTOS, E. A. A Cultura do feijão-caupi no Brasil. Teresina, PI: Embrapa Meio-Norte, 2016.

BEZERRA, E. A. Respostas bioquímicas comparativas de genótipos suscetíveis e resistentes de feijão-de-corda [Vigna unguiculata (L.) WALP.] desafiados com o vírus do mosaico severo do caupi (CPSMV). 2016. Dissertação (Mestrado em Bioquímica) - Universidade Federal do Ceará, Fortaleza, 2016.

BHATTRAI, G.; SHI, A.; QIN, JUN.; WENG, Y.; MORRIS, B; PINNOW, D. L.; RAVELOMBOLA, W.; YANG, W.; DONG, L. Association analysis of Cowpea mosaic virus (CPMV) resistance in the USDA cowpea germplam collection. Euphytica. n.1, p. 3-14, jul. 2017.

BLEICHER, E.; SILVA, P. H. S. Manejo de Pragas. Viçosa, MG: Ed. UFV, cap. 8, p.171203, 2017.

CARVALHO, R.C.P; COSTA, C. L. Controle de viroses de plantas. Brasília: Ed. UnB, cap. 16, p. 593-650, 2015.

CHANDRASEKARAN, J.; BRUMIN, M.; WOLF, D.; KLAP, C.; PEARLMAN, J.; SHERMAN, A. ARAZI, T.; GAL-OL, A. Development of broad virus resistance in nontransgenic cucumber using CRISPR/Cas9 technology. Mol Plant Pathol. 2016.

CÔELHO, J. D. Produção de grãos - Feijão, milho e soja. Caderno setorial ETENE. Banco do Nordeste, n. 33, 2018.

DAMASCENO E SILVA, K. J.; ROCHA, M. M.; MENEZES-JÚNIOR, J. A. N. A cultura do feijão-caupi no Brasil. Embrapa Meio-Norte. p.6-12, 2016.

DIANESE, E. C.; MEDEIROS, R. B. Diagnose de vírus de plantas. Brasília: Ed. UnB, cap. 14, p. 475-509. 2015.

FAO (2018) - Production. Crops. Food and Agriculture Organization of the United Nations. [Cit. 2018.02.28] Disponível em: 〈http://www.fao.org.br >. Acesso em: 09 set. 2020.

FERERES, A.; RACCAH, B. Plant vírus tranmission by insects, eLS. 2015.

FERREIRA, A. D. C. L. Preferência de Aphis craccivora, Koach por variedades locais de feijão-de-corda oriundas de pentecoste, Ceará. 2015. Dissertação (Mestrado em Fitotecnia) Universidade Federal do Ceará, Fortaleza, 2015.

GONÇALVES, A. Cowpea (Vigna unguiculata L.Walp), a renewed multipurpose crop for a more sustainable agri-food system: nutritional advantages and constraints. Journal oflhe Science of Food and Agriculture, v. 96, n. 9, p. 2941-2951, 2016.

IBGE - Instituto Brasileiro de Geografia e Estatística. Produção Agrícola de feijão-caupi (2015). Brasília:Ministério do Planejamento, Orçamento e Gestão. Disponível em: http://www.sidra.ibge.gov.br/. Acesso em: 21 out. 2020.

JOSÉ, A. R. M.; FREIRE FILHO, F. R.; CORDOVIL, G. A.; JUNIOR, R. A. G. Avaliação da 
resistência de progênies f5:6 de feijão-de-metro ao CPSMV (Cowpea severe mosaic virus). 2019. 23 ${ }^{\circ}$ Seminário PIBIC- 2019 Embrapa Amazônia Oriental. Disponível em:< https://www.alice.cnptia.embrapa.br>. Acesso em: 21 out. 2020.

KAUFMANN, C. M.; CORDOVIL, G. A.; BOARI, A. J.; GOMES, R. A.; FREIRE FILHO, F. R. Reação de genótipos de feijão-caupi tipo manteiguinha ao Cowpea severe mosaic vírus.2019. $2^{\circ}$ Seminário PIBIC- 2019 Embrapa Amazônia Oriental. Disponível em:< https://www.alice.cnptia.embrapa.br>. Acesso em: 21 out. 2020.

LAMAS, N. S.; MATOS, V. O. R. L.; ALVES-FREITAS, D. M. T.; MELO, F. L.; COSTA, A. F.; FARIA, J. C.; RIBEIRO, S. G. Occurrence of Cowpea mild mottle vírus in common bean and associeated weeds in Northeastern Brazil. Plant Disease, v. 101, p. 1828, 2017.

LIMA, C.S. Manejo de doenças. Viçosa: Editora UFV. p.143-170, 2017.

LIMA, J. A. A. Virologia essencial e viroses em culturas tropicais. Fortaleza: Edições UFC, p.605, 2015.

LIMA, L. F. Herança e incorporação de gene de resistência ao cowpea severe mosaic virus em genótipos de feijão-caupi da subclasse manteiga. 2019. Dissertação (Conclusão de cursoMelhoramento de plantas) - Universidade Federal Rural da Amazônia, Belém, 2019.

LINHARES, C. M. S.; FREITAS, F. C. L.; AMBRÓSIO, M. M. Q.; NUNES, G. H. S.; SILVA, K.S. Efeito de coberturas do solo sobre a podridão cinzenta do caule em Vigna unguiculata. Summa Phytopathologica, v.44, n.2, p.148-155, 2018.

OLIVEIRA, R. S. et al. Improved grain yield of cowpea (Vigna unguiculata) under water déficit after inoculation with Bradyrhizobium elkanii and Rhizophagus irregularis. Crop and Pasture Science, v. 68, n. 11, p. 1052-1059, 2017.

PIO-RIBEIRO, G.; ASSIS FILHO, F. M. ANDRADE, G.P. Manual de Fitopatologia. vol. 2, ed.5, Ouro Fino-MG: Agronômica Ceres, cap. 38, p. 373-381, 2016.

SILVA, A. F. Variabilidade entre isolados de Cowpea severe mosaic virus por meio de caracterização biológica, sorológica e molecular. 2017. Dissertação (Doutorado em Fitotecnia) - Universidade Federal do Ceará, Fortaleza, 2017.

SILVA, P. H. S.; ATHAYDE SOBRINHO, C. Guia prático de reconhecimento e controle das principais pragas do feijão-caupi. Embrapa Meio Norte. Teresina-PI, 2019.

SOUZA, S. M. S. Variabilidade morfoagronômica de variedades tradicionais de feijão-caupi do acre. 2016, 69 p. Dissertação (Mestrado) - Universidade Federal do Acre. Rio Branco, AC, 2016.

THOMPSON, J. R.; DASGUPTA, I.; FUCHS, M.; IWANAMI, T.; KARASEV, A. V.; PETRZIK, K.; SANFAÇON, H.; TZANETAKIS, I. E; VANDER, R.; WETZEL, T.; YOSHIKAWA, N.Vírus Taxonomy. Journal of General Virology, v. 98, p.529-531, 2017.

VALE, J. C.; BERTINI, C.; BORÉM, A. Feijão-Caupi: do plantio à colheita. 1. Ed., Viçosa, p.267, 2017. 
OLIVEIRA, et al. 